\title{
Bem Estar Pessoal e Sentimento de Comunidade: um estudo psicossocial da pobreza ${ }^{1}$
}

\author{
Personal Well-being and Sense of Community: a psychosocial study of poverty
}

\author{
Bárbara Barbosa Nepomuceno ${ }^{\mathrm{I}}$ \\ Marília Studart Barbosa ${ }^{\mathrm{II}}$ \\ Verônica Morais Ximenes ${ }^{\text {III }}$ \\ Antônio Alan Vieira Cardoso IV
}

\section{Resumo}

O estudo objetivou analisar as implicaçóes psicossociais da pobreza, a partir do bem estar pessoal e sentimento de comunidade, em populaçôes de comunidades rural e urbana do Ceará (Brasil). A pesquisa quantitativa contou com amostra de 411 sujeitos adultos. Aplicou-se questionários compostos por: itens de identificação, Instrumento de Mensuraçáo da Pobreza Multidimensional, Sense of Community Index (SCI) e Personal Well-Being Index (PWI). Os resultados indicam média de pobreza multidimensional no contexto rural $(\mathrm{M}=0,28)$ maior que no urbano $(\mathrm{M}=0,23)$, entretanto o primeiro apresenta maiores médias de sentimento de comunidade e bem estar pessoal. Tais categorias apresentam correlação positiva $(\mathrm{r}=0,305)$. Os aspectos psicossociais da pobreza interagem com o contexto sociocultural assumindo diferentes configuraçôes nos cenários urbano e rural.

Palavras chave: Pobreza; Psicologia; Bem Estar Pessoal; Sentimento de Comunidade.

\section{Abstract}

This study aimed to analyze the psychosocial implications of poverty based on Personal Well-being and on Sense of Community in populations of rural and urban communities of Ceará (Brazil). The quantitative research included a sample of 411 participants. The questionnaires were composed of identification items, Measurement Index of the Multidimensional Poverty, Sense of Community Index (SCI) and Personal Well-Being Index (PWI). The results indicate a mean of multidimensional poverty in the rural context $(\mathrm{M}=0.288)$ higher than in the urban context $(\mathrm{M}=0.23)$. However, the first one shows higher meanings of Sense of Community and Personal Well-being. These categories showed positive correlation $(r=0.305)$. The psychosocial aspects of poverty interact with the sociocultural context creating different configurations in the urban and rural areas.

Keywords: Poverty; Psychology; Personal Well-being; Sense of Community.

${ }^{\mathrm{I}}$ Programa de Pós - Graduação em Psicologia da Universidade Federal do Ceará, Fortaleza

II Programa de Pós - Graduação em Psicologia da Universidade Federal do Ceará, Fortaleza

III Programa de Pós - Graduação em Psicologia da Universidade Federal do Ceará, Fortaleza

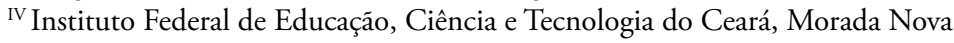

A pobreza, um fenômeno constituído e mantido no seio do capitalismo (Stotz, 2005), historicamente assumiu diferentes conceituaçôes na busca por identificar um enquadramento para os sujeitos que se encontram em condição de privação e vulnerabilidade social (Accorssi, 2011; Loureiro \& Suliano, 2009). Pesquisas sobre a pobreza destacam haver duas grandes perspectivas de análise: as unidimensionais e as multidimensionais (Accorssi, 2011; Moura Jr., Cidade, Ximenes \& Sarriera, 2014). As primeiras analisam o fenômeno em função de apenas um único fator, como por exemplo, uma análise baseada nas necessidades nutricionais ou na abordagem monetária. Segundo Moura Jr., Cidade, Ximenes e Sarriera (2014), tais perspectivas são insuficientes a uma compreensão da experiência da vida em condiçôes de pobreza, pois desconsidera, diversos aspectos como saúde, educaçáo, trabalho, renda, lazer, esporte dentre outros. Destacam ainda, os autores, que a leitura do fenômeno unicamente sob o prisma monetário “... é portadora de elementos ideológicos, políticos e psicológicos específicos e limitados” (p.342).

O reconhecimento das limitaçôes das análises unidimensionais e de que a pobreza se manifesta de maneira complexa possibilitou o surgimento das leituras multidimensionais da pobreza. Amartya Sen, economista indiano, trará importantes contribuiçôes neste sentido. Segundo o mesmo, a pobreza deve ser compreendida como privação das capacidades básicas e da liberdade do indivíduo (Sen, 2010). Neste sentido, na análise do fenômeno devem-se considerar as diversas formas de privaçáo: de igualdade de gênero, de acesso a serviços de saúde, de educação de qualidade,

1 Agradecimentos ao Ministério da Ciência, Tecnologia e Inovação - MCTI e o Ministério da Educação, por intermédio do Conselho Nacional de Desenvolvimento Científico e Tecnológico - CNPq e da Coordenação de Aperfeiçoamento de Pessoal de Nível Superior - CAPES, pelo financiamento da pesquisa através do Edital MCTI /CNPq /MEC/CAPES N o 07/2011. 
de segurança, da liberdade civil, política e da liberdade básica de sobreviver, dentre outras.

Ademais a pobreza influi na produção de formas singulares de estruturação do psiquismo. $\mathrm{O}$ fenômeno tem uma expressão inter e intrapsicológica que conduz açôes, sentimentos e significaçóes relacionados às privaçóes vividas, que implicam um tipo de existência, uma forma de estar no mundo (Bastos, Rabinovich, \& Almeida, 2010). Para Nepomuceno (2013, p.39) “. . . ser pobre não implica somente privação material, mas um modo de vida, uma expressão da existência possível a partir das pré-condiçóes estruturais sociais e econômicas".

Desta forma, compreende-se que a Psicologia pode trazer importantes contribuiçôes na análise de categorias psicossociais como sentimento de comunidade, bem estar pessoal, dentre outras, pertinentes ao estudo da pobreza. Neste sentido, objetiva-se neste artigo analisar as implicaçóes psicossociais da pobreza, a partir das categorias bem estar pessoal (Sarriera et al., 2012) e sentimento de comunidade (Sarason, 1974), em populaçóes de uma comunidade rural e uma urbana do nordeste brasileiro.

Sentimento de comunidade, sentido de comunidade, senso de comunidade, sentido psicológico de comunidade são traduçôes possíveis para Sense of Community, termo criado por Seymour Sarason, em 1974 (Amaro, 2007). Apesar das múltiplas traduçôes possíveis, neste artigo, utiliza-se o termo Sentimento de Comunidade, por compreendê-lo como o que mais se aproximada da conceituaçáo do autor, definido como "o sentimento de que somos parte de uma rede de relacionamentos de suporte mútuo, sempre disponível e da qual podemos depender" (Sarason, 1974, p. 1, tradução nossa). Considerado, portanto, como um sentimento de pertença a uma rede de relaçóes, a interdependência voluntária e a mutualidade.

Segundo McMillan e Chavis (1986), o Sentimento de Comunidade constitui-se como o sentimento de ser parte da comunidade, de pertencer a esta, de se importar com as pessoas do lugar e de se sentir importante para elas. Relaciona-se a uma fé de que o compromisso de estar em coletividade é capaz de satisfazer necessidades pessoais. Considerando as contribuições do conceito para a análise do fenômeno da pobreza, cabe investigar como indivíduos e coletividades se organizam a fim de resolver problemáticas encontradas cotidianamente. Para McMillan e Chavis (1986), o sentimento de comunidade é composto por quatro dimensões: integração e satisfação das necessidades; filiação; influência e ligação emocional compartilhada. A dimensão filiação refere-se a um sentimento de perceber-se como membro, como parte de uma coletividade (McMillan \& Chavis, 1986), envolve a história, a identidade social e os símbolos compartilhados em uma comunidade (Montero, 2004) e implica relações de lealdade (Marante, 2010). A influência, por sua vez, expressa uma relação bidirecional entre os membros de uma coletividade, na qual cada um influencia e é influenciado pelo grupo (McMillan \& Chavis, 1986), sendo essa dimensão importante à unidade e coesão no grupo (Montero, 2004). A dimensão integração e satisfação das necessidades está relacionada ao sentimento de que as necessidades dos membros podem ser satisfeitas pelos recursos disponíveis graças à condição de ser parte do grupo (McMillan \& Chavis, 1986). De acordo com Montero (2004), esta última relaciona-se aos benefícios que a pessoa pode adquirir por fazer parte da comunidade, como status, popularidade, valores compartilhados, ajuda material e psicológica, entre outros. E por fim, a dimensão ligação emocional compartilhada, destaca as relaçóes de proximidade e os laços afetivos estabelecidos entre as pessoas da comunidade, o que possibilita uma história partilhada na qual as pessoas se identificam e incorporam suas histórias particulares (McMillan \& Chavis, 1986).

Para Montero (2004), o conceito sentimento de comunidade não é de fácil definição e supóe uma concepção de comunidade, a partir da qual deve ser construído tal termo. Góis (2005) afirma ser a comunidade um espaço físico, cultural, social e psicológico, que possui uma dimensão física, geográfica-territorial. Tal autor apresenta uma concepçáo da comunidade na qual o sentimento de comunidade se faz necessário e imprescindível, no qual se fazem presentes os sentimentos de pertença, de partilha entre os membros e o estabelecimento de laços afetivos que possibilitam histórias de vida compartilhadas.

No intuito de investigar a importância do sentimento de comunidade, como um elemento protetivo a sujeitos e coletividades, estudos têm demonstrado seus efeitos positivos para indivíduos e comunidades, como a satisfação e qualidade de vida (Elvas \& Moniz, 2010), o bem-estar (Morais, 2010), a qualidade de vida subjetiva percebida, autoconfiança e maior capacidade de mobilização e participação das pessoas na resolução de seus problemas (Prezza \& Constantini, 1998). O sentimento de comunidade também contribui para o fortalecimento das redes comunitárias (Freitas \& Montero, 2003) e do apoio social (Garcia \& Herrero, 2006). Isso demonstra a importância das articulaçóes entre pessoas e grupos unidos em prol de um objetivo comum, ampliando as possibilidades de desenvolvimento pessoal e local e de enfrentamento das adversidades cotidianas. 
Neste sentido, o sentimento de comunidade caracteriza-se como importante aos contextos de vulnerabilidade social, marcados pela pobreza e exclusáo social.

Estudos sobre qualidade de vida e bem estar emergem de forma significativa a partir da década de 1960, no contexto de surgimento do Estado de Bem Estar Social no período pós Segunda Guerra. Com a criaçáo de tais conceitos teóricos, busca-se avaliar e medir as condiçóes de vida das pessoas e possibilitar a realizaçáo de açôes que alterem os processos de marginalização social de contextos específicos (Martínez, 2004).

Assim como no conceito de sentimento de comunidade, uma das características da categoria bem estar é sua diversidade teórica, que pode ser verificada na multiplicidade de termos bem estar pessoal, bem estar psicológico, satisfação com a vida, entre outros, muitas vezes usados como sinônimos (Benatuil, 2003). Segundo Benatuil (2003), a grande quantidade de estudos empíricos sobre bem estar não tem sido acompanhados do desenvolvimento de constructos teóricos que os respaldem. Neste estudo, opta-se pelo termo bem estar pessoal uma vez que ele tem sido a expressão mais utilizada nas pesquisas (Sarriera et al., 2012) e por se mostrar como satisfatório para as finalidades deste artigo.

O bem estar pessoal se refere a "sentir-se globalmente bem ao longo do ciclo vital" (Sarriera et al., 2012, p. 92). O estudo de tal categoria busca compreender variáveis que envolvem uma avaliação global sua vida como globalmente, em função dos aspectos satisfatório e insatisfatórios. Segundo Casas e Bello (2012, p. 29, tradução nossa), "o bem-estar subjetivo para muitos autores é fundamental sentir-se bem, desfrutar e estar contente". Cummins, Eckersley, Pallant, Van Vugt e Misajon (2003) analisam o bem estar pessoal a partir das dimensóes: nível de vida, saúde, realização na vida, relacionamentos, segurança, conexão com a comunidade, futuro e espiritualidade/religião que estão compostas na Escala de Bem Estar Pessoal (Personal Well-Being Index-PWI) que avalia a média de satisfação do sujeito nesses diferentes âmbitos da vida.

$\mathrm{O}$ estudo sobre bem estar pessoal em populaçóes pobres se justifica na medida em que a pobreza implica uma série de desdobramentos psicológicos, que repercutem nessas dimensôes anteriormente mencionadas. Independente da perspectiva de pobreza adotada, os estudos revelam que o baixo bem estar está associado a um conjunto de carências da vida nessas condiçôes (Lever, Piñol \& Uralde, 2005). É importante destacar que a relação entre o bem estar pessoal e a pobreza também ganha relevância quando se parte de uma compreensão multidimensional (Sen, 2010) desta, considerando suas implicaçôes psicológicas (Cidade, Moura Jr., \& Ximenes, 2012).
Desta forma, investigações sobre bem estar pessoal e sentimento de comunidade podem contribuir para uma maior compreensão das implicaçóes psicossociais da pobreza na vida dos sujeitos, uma vez que tais categorias expressam tanto aspectos que priorizam a vida pessoal dos indivíduos quanto da vida destes em coletividade/comunidade. Desta forma, permite-se uma avaliação do impacto subjetivo da vivência dos sujeitos em contextos de privação, como também, o conhecimento de estratégias de enfrentamento às adversidades vividas cotidianamente.

\section{Método}

A presente pesquisa se caracteriza como exploratória, tendo por finalidade conhecer as variáveis de estudo tal como se apresentam, seu significado e o contexto onde se inserem (Piovesan \& Temporini, 1995). A pesquisa teve um caráter quantitativo, utilizando-se de um questionário composto por questôes sociodemográficas e por escalas psicométricas.

\section{Participantes}

A pesquisa foi realizada em duas comunidades do Estado do Ceará: uma situada no contexto urbano, localizada na periferia de Fortaleza e outra no contexto rural, localizada em Apuiarés, distante $134 \mathrm{~km}$ da capital. Ambas as comunidades foram escolhidas por serem lócus de projetos de atuação, nos quais os pesquisadores envolvidos participavam, o que facilita a inserção no campo de pesquisa, além de se configurarem como comunidades em condiçôes de vulnerabilidade social.

A comunidade urbana possui uma população de 37.758 habitantes, dos quais aproximadamente $8,11 \%$ vivem em extrema pobreza (IPECE, 2012). Em relação índices de Desenvolvimento Humano Municipal (IDH-M), obteve a pontuação média de 0,403 , abaixo da média da capital (Universidade Estadual do Ceará, 2011). A comunidade rural, localizada na zona rural a $24 \mathrm{~km}$ da sede de Apuiarés, pertence a um município com população estimada em 13.925 habitantes, média do IDH-M de 0,618 e com 37,84\% da população rural vivendo em extrema pobreza (IPECE, 2013). As atividades prioritárias que garantem a subsistência da população local, são: agricultura familiar, benefícios sociais, funcionalismo público e aposentadorias.

A amostra geral da pesquisa foi composta por 417 sujeitos, sendo $28,1 \%$ homens $(\mathrm{N}=177)$ e 71,9 $\%$ mulheres $(\mathrm{N}=299)$, de idade entre 18 e 88 anos e 208 moradores da comunidade de rural e 209 da 
urbana. Com relação à renda familiar, 25,2\% $(\mathrm{N}=105)$ das pessoas têm renda mensal inferior à 85 reais, 54,7\% $(\mathrm{N}=228)$ possuem renda entre 85 e 678 reais e $20,1 \%$ $(\mathrm{N}=84)$ das pessoas possuem uma renda superior à 678 reais. Os critérios utilizados para a escolha dos participantes do estudo foram: ter mais de 18 anos, morar na comunidade por no mínimo 1 ano, declarar sua anuência ao estudo após ciência do termo de consentimento e demais informações sobre a pesquisa.

\section{Procedimentos de Construção e Análise dos Dados}

$\mathrm{Na}$ coleta de dados foram aplicados questionários com questóes fechadas de forma individual nas casas das pessoas. Durante este momento foram priorizadas regiôes onde se concentravam as populaçóes mais vulneráveis, tal escolha foi orientada por informantes chaves da comunidade (lideranças comunitárias, profissionais de políticas públicas e projetos sociais). Os questionários continham os seguintes componentes: Itens de identificação do perfil da amostra, Instrumento de Mensuração da Pobreza Multidimensional, Sense of Community Index (SCI) e o Personal Well-Being Index (PWI).

O Instrumento de Mensuração da Pobreza Multidimensional, elaborado por Ximenes, Moura Júnior, Cruz, Silva e Sarriera (2016), visa avaliar a pobreza multidimensional a partir de 24 itens que se agrupam em 5 grandes dimensóes, a saber: habitação, escolaridade, trabalho/renda, saúde e aspectos subjetivos da pobreza. $\mathrm{O}$ instrumento mensura a pobreza multidimensional, a partir da metodologia de conjunto fuzzy que indica diferentes graus de realização de cada indicador. Desta forma, os itens recebem uma pontuação entre 0 e 1 , na qual quanto mais próximo de 1 , mais pobres são os sujeitos e quanto mais próximo de 0 , menos pobres serão. Cada dimensão possui o mesmo peso na composição da média final gerada.

O Sense of Community Index (SCI), elaborado por McMillan e Chavis (1986), se propóe a avaliar o Sentimento de Comunidade a partir das dimensôes filiação; influência; integração e satisfação de necessidades; e ligaçóes emocionais partilhadas. Já o Personal Well-Being Index - PWI (Cummins et al., 2003) é composto por itens que avaliam a média de satisfação com diferentes âmbitos da vida através de uma escala Likert, a saber: nível de vida, saúde, realização na vida, relacionamentos, segurança, conexão com a comunidade, futuro, segurança e espiritualidade/religiáo. Ambas as escalas utilizadas no estudo foram validas para o Brasil.

Os dados provenientes do questionário foram organizados a partir do pacote estatístico SPSS (Statistical Package for Social Sciences) 20.0 e realizadas as seguintes análises: estatística descritiva, Teste t de Student para amostras independentes, correlação de Pearson e correlação de Spearman. Em respeito aos parâmetros e itens que regem a Resolução 466, de 2012, do Conselho Nacional de Saúde do Brasil, que regulamenta pesquisa com seres humanos no Brasil, a pesquisa foi submetida ao Comitê de Ética em Pesquisa, sendo aprovada com CAAE: 07810512.3.0000.5054 e Parecer No 191.508.

\section{Resultados}

Com um número válido de 411 sujeitos, a média geral do Instrumento de Pobreza Multidimensional (IPM) foi de $0,25(\mathrm{DP}=0,11)$. Os resultados em função do contexto apontam que a média de pobreza do contexto rural $(\mathrm{M}=0,288 ; \mathrm{DP}=0,10)$ é maior que a do urbano $(M=0,23 ; \mathrm{DP}=0,11)$, sendo a diferença entre elas significativa $(\mathrm{t}(339)=-4,649, p=0,00)$. A análise de correlação entre pobreza e bem estar pessoal indica que a relação entre as variáveis é negativa e significativa no contexto urbano $(r=-0,25, p<0,001)$ e negativa e náo significativa no contexto rural $(r=-0,51, p>0,001)$. Considerando as relações entre variáveis pobreza e sentimento de comunidade, esta náo foi significativa no contexto urbano $(\mathrm{r}=0,88, p>0,001)$, assim como no contexto rural $(r=-0,73, p>0,001)$.

Tomando a análise das variáveis anos de estudo e renda individual e familiar, em função da variável dependente bem estar pessoal observa-se que: a relação desta com anos de estudo ocorreu de forma negativa e estatisticamente significativa $\left(\mathrm{r}_{s}=-0,25, p=0,000\right)$; e com renda familiar $(\mathrm{r}=0,66, p>0,001)$ e individual $(\mathrm{r}=0,15, p>0,001)$ náo implicou em médias de bem estar pessoal significativamente diferentes. A média de bem estar pessoal das pessoas que náo estudaram $(M=8,42, D P=1,63)$ foi maior do que a encontrada entre os que estudaram 12 anos ou mais $(M=7,62$, $\mathrm{DP}=1,51)$. Considero a análise das mesmas variáveis independentes com sentimento de comunidade, os resultados indicam que: a relação é negativa e significativa entre anos de estudo sentimento de comunidade $(r=-0,274, p=0,000)$; e não é significativa entre renda individual $\left(r_{s}=0,129, p>0,001\right)$ e renda familiar $\left(r_{s}=\right.$ - 0,013, $p>0,001)$.

A média geral do Sentimento de Comunidade foi de 2,37 ( $D P=0,55)$, que se situa no intervalo entre os valores moderado e baixo. $\mathrm{Na}$ Tabela 1, pode-se observar a média e o desvio padrão dos itens da escala de Sentimento de Comunidade ligados às dimensôes integração e satisfação das necessidades; filiação; influência e ligação emocional compartilhada de cada uma das comunidades. 


\section{Tabela 01}

Resultados da Escala de Sentimento de Comunidade (Estatística Descritiva)

\begin{tabular}{|c|c|c|c|c|c|}
\hline Fatores* & Itens & $\begin{array}{c}\text { Tipo de } \\
\text { comunidade }\end{array}$ & $\mathbf{N}$ & Média & Desvio Padráo \\
\hline \multirow{3}{*}{ ISN } & \multirow{3}{*}{$\begin{array}{l}\text { Meus vizinhos e eu queremos } \\
\text { coisas semelhantes }\end{array}$} & Urbana & 208 & 1,96 & 1,11 \\
\hline & & Rural & 203 & 2,27 & 0,97 \\
\hline & & Total & 411 & 2,11 & 1,05 \\
\hline \multirow{3}{*}{$\mathrm{F}$} & \multirow{3}{*}{$\begin{array}{l}\text { Eu consigo reconhecer muitas } \\
\text { pessoas que vivem no meu bairro }\end{array}$} & Urbana & 207 & 2,57 & 1,04 \\
\hline & & Rural & 202 & 3,03 & 0,69 \\
\hline & & Total & 409 & 2,80 & 0,91 \\
\hline \multirow{3}{*}{$\mathrm{F}$} & \multirow{3}{*}{ Eu me sinto em casa nesse bairro } & Urbana & 207 & 2,71 & 1,11 \\
\hline & & Rural & 203 & 3,14 & 0,75 \\
\hline & & Total & 410 & 2,92 & 0,97 \\
\hline \multirow{3}{*}{ I } & \multirow{3}{*}{$\begin{array}{l}\text { Eu me importo com o que os meus } \\
\text { vizinhos pensam das minhas açôes }\end{array}$} & Urbana & 207 & 1,63 & 1,30 \\
\hline & & Rural & 203 & 1,52 & 1,08 \\
\hline & & Total & 410 & 1,58 & 1,19 \\
\hline \multirow{3}{*}{ I } & \multirow{3}{*}{$\begin{array}{l}\text { Se houver um problema nesse } \\
\text { bairro, as pessoas que vivem } \\
\text { aqui podem resolvê-lo. }\end{array}$} & Urbana & 207 & 1,71 & 1,12 \\
\hline & & Rural & 203 & 2,22 & 0,96 \\
\hline & & Total & 410 & 1,96 & 1,07 \\
\hline \multirow{3}{*}{ LEC } & \multirow{3}{*}{$\begin{array}{l}\text { É muito importante para } \\
\text { mim viver nesse bairro }\end{array}$} & Urbana & 207 & 2,39 & 1,18 \\
\hline & & Rural & 204 & 3,04 & 0,78 \\
\hline & & Total & 411 & 2,72 & 1,05 \\
\hline \multirow{3}{*}{ LEC } & \multirow{3}{*}{$\begin{array}{l}\text { Eu espero viver nesse bairro } \\
\text { por um longo tempo }\end{array}$} & Urbana & 207 & 2,24 & 1,33 \\
\hline & & Rural & 204 & 2,91 & 0,97 \\
\hline & & Total & 411 & 2,57 & 1,21 \\
\hline \multirow{3}{*}{$\mathrm{F}$} & \multirow{3}{*}{ Poucos vizinhos me conhecem } & Urbana & 206 & 2,38 & 1,24 \\
\hline & & Rural & 198 & 2,94 & 0,85 \\
\hline & & Total & 404 & 2,66 & 1,10 \\
\hline \multirow{3}{*}{ LEC } & \multirow{3}{*}{$\begin{array}{l}\text { Pessoas nesse bairro/comunidade } \\
\text { geralmente não se dão bem }\end{array}$} & Urbana & 206 & 1,87 & 1,04 \\
\hline & & Rural & 204 & 2,20 & 1,02 \\
\hline & & Total & 410 & 2,03 & 1,05 \\
\hline
\end{tabular}

Fonte: Elaborado pelos autores.

*Integração e Satisfação das Necessidades (ISN); Filiação (F); Influência (I) e Ligação Emocional Compartilhada (LEC)

A realização do Test $t$, para amostras independentes, revela que a diferença das médias do Sentimento de Comunidade entre os contextos urbano e rural é significativa $(t(399)=-8,293, p=0,000)$. Na comunidade rural, a média foi de $2,58(\mathrm{DP}=0,36)$, enquanto que na urbana essa média foi menor, sendo $2,15(\mathrm{DP}=$ 0,62). Considerando a amostra total, o item com maior nível de concordância entre os entrevistados, de acordo com a Tabela 1, foi "Eu me sinto em casa nesse bairro" $(\mathrm{M}=2,92 ; \mathrm{DP}=0,97)$, seguido pelo item "Eu consigo reconhecer muitas pessoas que vivem no meu bairro"
$(\mathrm{M}=2,80 ; \mathrm{DP}=0,91)$. Ambos os itens relacionam-se à dimensão filiação (McMillan \& Chavis, 1986).

Os dois itens, de acordo com a Tabela 1, que obtiveram a menor pontuação, na amostra total foram: o "Eu me importo com o que os meus vizinhos pensam das minhas açôes" ( $M=1,58 ; \mathrm{DP}=1,19)$ e o "Se houver um problema nesse bairro as pessoas que vivem aqui podem resolvê-lo" $(\mathrm{M}=1,96$; $\mathrm{DP}=1,07)$, ambos relacionados à dimensão influência.

De acordo com os resultados da amostra, existe uma correlação positiva entre as médias do bem estar 
pessoal e do sentimento de comunidade $(r=0,305$, $\mathrm{p}<0,001)$. No que concerne aos resultados específicos ao bem estar pessoal (Tabela 2), a média geral da amostra de sujeitos das comunidades urbana e rural foi de 7,96 ( DP= 1,51), o que é considerada uma média alta, tendo em vista a variação entre 0 e 10 . Levando-se em consideração as amostras rural e urbana os resultados revelam que a média de bem estar na comunidade rural $(\mathrm{M}=8,28, \mathrm{DP}=1,27)$ foi maior do que na comunidade urbana $(\mathrm{M}=7,64, \mathrm{DP}=1,67)$. Essa diferença foi estatisticamente significativa $(\mathrm{t}(386)=-4,203, \mathrm{p}<0,001)$.
Conforme pode-se observar na Tabela 02, o item da escala PWI que teve a maior média, para a amostra total, foi o "Satisfação em relação à espiritualidade ou crenças religiosas" ( $\mathrm{M}=8,84, \mathrm{DP}=1,84)$, seguido do "Satisfação com as relaçóes com outras pessoas" $(\mathrm{M}=8,38, \mathrm{DP}=1,997)$. Percebe-se que a menor média de Bem Estar Pessoal $(M=6,75, D P=3,07)$ foi encontrada no item "Satisfação com a sensação de estar seguro", apresentando média de 6,02 (DP= $3,33)$ na comunidade urbana e $7,49(\mathrm{DP}=2,59)$ na comunidade rural.

\section{Tabela 02}

Resultados da Escala de Bem Estar Pessoal (Estatística Descritiva)

\begin{tabular}{ccccc}
\hline Itens & Tipo de & N & Média & $\begin{array}{c}\text { Desvio } \\
\text { Padráo }\end{array}$ \\
\hline comunidade & Urbana & 207 & 7,12 & 2,91 \\
Satisfação com sua saúde & Rural & 202 & 8,02 & 2,27 \\
Satisfação com o seu nível de vida & Total & 409 & 7,56 & 2,65 \\
Satisfação com as coisas que você & Urbana & 203 & 7,33 & 2,59 \\
tem conseguido na vida & Rural & 204 & 8,28 & 1,60 \\
& Total & 407 & 7,80 & 2,20 \\
Satisfaçáo com sensação de estar seguro(a) & Urbana & 204 & 7,96 & 2,43 \\
Satisfação com os grupos de pessoas & Rural & 204 & 8,48 & 1,83 \\
dos quais você é parte & Total & 408 & 8,22 & 2,16 \\
& Urbana & 206 & 6,02 & 3,33 \\
Satisfação com a segurança a respeito do futuro & Rural & 204 & 7,49 & 2,59 \\
Satisfaçáo com a sua espiritualidade & Total & 410 & 6,75 & 3,07 \\
ou crenças religiosas & Urbana & 206 & 8,31 & 1,12 \\
& Rural & 204 & 8,42 & 2,27 \\
& Total & 410 & 8,36 & 2,00 \\
& Urbana & 206 & 7,09 & 2,82 \\
& Rural & 204 & 7,97 & 1,94 \\
& Total & 410 & 7,53 & 2,46 \\
& Urbana & 209 & 8,09 & 2,31 \\
& Rural & 203 & 8,68 & 1,55 \\
& Total & 412 & 8,38 & 1,99 \\
& Urbana & 208 & 8,84 & 2,00 \\
& Rural & 204 & 8,84 & 1,65 \\
& Total & 412 & 8,84 & 1,84 \\
\hline
\end{tabular}

Fonte: Elaborado pelos autores.

\section{Discussáo}

Os maiores indicadores de pobreza multidimensional no contexto rural quando comparados ao urbano corrobora com a literatura científica disponível (Soares, Souza, Silva, Silveira, \& Campos, 2016). Somado a isto, o fato de que mesmo em piores condiçóes de pobreza o contexto rural apresentar maiores indicadores de bem estar pessoal e sentimento de comunidade, explicita a complexidade necessária na leitura da realidade social da pobreza, que deve sempre considerar as características do contexto social, regional e local onde se expressa. 
A manifestação de um maior sentimento de comunidade no contexto rural pode relacionar-se às configuraçóes do contexto urbano. Tal fato corrobora os estudos de Prezza e Constantini (1998) que revelam uma maior média do sentimento de comunidade em cidade de pequeno porte. Ximenes e Moura Jr. (2013) destacam como próprias ao urbano a grande mobilidade, o medo da violência e uma grande valorização da individualidade. Para tais autores, no espaço rural, fortemente marcado pela pobreza, percebe-se uma maior vinculação entre os moradores e familiares. Entretanto, a pontuaçáo baixa a moderada do sentimento de comunidade nos dois cenários, pode indicar que o campo, na atualidade, também está sendo atravessado pela valorização do individualismo e pela fragilização os laços sociais, próprias à cultura capitalista.

Considerando as altas médias de bem estar pessoal encontradas, Dela Coleta, Lopes e Dela Coleta (2012) afirmam que sujeitos brasileiros tendem a se posicionar em torno da média ou em posição superior em relação a sujeitos de outros países nos aspectos que mensuram felicidade e bem-estar, mesmo quando se controlam os efeitos relacionados aos fatores econômicos. Casas e Bello (2012) destacam a presença de um otimismo vital no funcionamento normal do bem-estar em todas as culturas, propondo a existência de uma homeostase cultural do bem estar. As maiores medias de bem estar pessoal, encontrados na comunidade rural, coadunam com os estudos de Cummins et al. (2003) que afirmam haver uma maior média em populaçôes rurais.

O fato de que as variaçóes de renda dos sujeitos não implicaram em diferenças significativas nas médias de bem estar pessoal vão de encontro a outras pesquisas que evidenciam correlações positivas e significativas entre felicidade e renda (Oliveira et al., 2009; Dela Coleta, Lopes \& Dela Coleta, 2012). Esse resultado reforça a afirmação de Diener e Seligman (2004) de que o progresso econômico, apesar de poder melhorar a qualidade de vida das pessoas, já não serve como um forte medidor de bem estar por haver discrepâncias substanciais entre os índices econômicos e outras mensuraçôes que compóem a avaliação do bem estar.

A variável anos de estudo evidenciou que quanto maior o grau de instrução, menor os indicadores de bem estar. Tal resultado pode estar relacionado ao fato de que quanto mais escolarizados, os sujeitos tenderão a avaliar a vida a partir de uma gama maior de fatores, isto pode levar a uma maior insatisfaçáo com a vida. Outro fator pode ser a presença de um maior conformismo entre pessoas de baixa escolaridade, o que pode favorecer a uma cultura de resignaçáo, do "não reclamar" mesmo frente à grandes adversidades vividas. Sobre este último ponto, Góis (2005) destaca a presença de uma ideologia de submissão e resignação fortemente presente na sociedade, em especial entre pessoas em situaçóes de maior vulnerabilidade social.

Os resultados que mostram que maiores médias de bem estar pessoal relacionam-se com maiores médias de sentimento de comunidade confirmam os estudos de Amaro (2007), Elvas e Moniz (2010) e Morais (2010). Tal resultado corrobora a questáo de que vínculos sociais está relacionada a aspectos relativos ao bem estar. De acordo com Diener e Seligman (2004), este pode ser percebido através da qualidade das relaçóes sociais das pessoas, do apoio que recebem umas das outras e do pertencimento social. Demonstram, ainda, que as pessoas tendem a apresentar sofrimento quando têm restritas redes sociais ou quando têm relaçôes frágeis dentro destas. Neste sentido, se questiona se a participação em grupos pode ser um fator favorável ao bem-estar. Por conseguinte, pode-se problematizar se ao trabalhar o fortalecimento das redes comunitárias, podese esperar benefícios como a melhoria do bem estar e qualidade de vida de pessoal e das comunidades, assim como a ampliação do apoio social. Este último, segundo Silva, Feitosa, Nepomuceno, Silva, Ximenes e Bomfim (2016), é um importante recurso de enfretamento às problemáticas da vida em condiçóes de pobreza.

Os resultados apresentados em relação ao sentimento de comunidade revelaram que os itens da dimensão "Filiação" (McMillan \& Chavis, 1986) tiveram as maiores médias, o que revela um território físico e emocional que define o que faz parte ou não da coletividade, fundamental à existência de um sentimento de segurança emocional nos sujeitos da comunidade (Amaro, 2007). Os itens da dimensão "Influência" apresentaram as menores médias, o que revela uma fragilidade no sentimento de coesão do grupo, na percepçáo de que os sujeitos se influenciam mutuamente, assim como de que podem interferir no desenvolvimento da comunidade, aspectos que, segundo Montero (2004), são fundamentais à participação comunitária.

A fragilizaçáo dos laços comunitários acaba por desmobilizar a organização comunitária, enfraquecendo a capacidade de ação dos sujeitos em prol de uma transformação da realidade. Tal fenômeno deve ser analisado sob as perspectivas macro e micro das relaçóes sociais dentro da sociedade capitalista neoliberal contemporânea e das suas formas atuais de sociabilidade. Estas são fortemente marcadas pela globalização e fragilização dos regionalismos, pelo individualismo e crescente presença das relaçóes voláteis, marcadas por descontinuidades e 
rupturas (Bauman, 2008). Isto dificulta a formação de identidades coletivas, compreendidas como "um processo dinâmico de construção de práticas coletivas que criam um conjunto de significaçóes interpretativas da estrutura e da hierarquia societal" (Prado, 2005, p. 53).

As maiores médias na escala de bem estar pessoal, relacionadas à satisfação com a espiritualidade e com as crenças religiosas, demonstram que o apoio da igreja e a experiência de fé aparecem como aspectos de suprimento das necessidades dos sujeitos. Os estudos de Diener e Seligman (2004) destacam que pessoas religiosas tendem, em média, à experiência de maior bem estar pessoal, quando comparadas a pessoas não-religiosas. A espiritualidade e a crença religiosa podem configurar-se ora como mecanismos de libertação ora como expressáo do fatalismo (Cidade, 2012). A vivência da espiritualidade, em contextos marcados pela pobreza, tem o duplo poder de ressignificar as situaçôes de opressão, possibilitando um poder de reação e por outro, reforçar posturas de resignação frente ao presente e ao futuro, percebendo a vida como um destino dado e incapaz de mudá-lo (Lima \& Valla, 2005).

A insatisfação em relação à sensação de segurança, presente nos sujeitos da comunidade urbana, relaciona-se tanto à problemática da violência vivida pela comunidade, como à estigmatização do território como violento. Tal questáo se apresentou em menor proporção no contexto rural.

\section{Consideraçóes finais}

Estudar a pobreza em uma perspectiva multidimensional, estando atentos às implicaçôes psicossociais que atravessam a sua produção, perpetuação e vivência requer dos pesquisadores o desenvolvimento de instrumentais diversificados e adequados a realidade sociocultural a ser investigada. Fica explicitado, neste estudo, que a vivência da pobreza ocorre de forma diferenciada nos contextos rurais e urbanos. No rural, a pobreza apresentará maiores indicadores, entretanto terá maiores indicadores de bem estar pessoal. O sentimento de comunidade apresenta resultados moderados a baixo tanto no contexto rural quanto no urbano, porém a diferença entre os dois cenários é significativa. Isto revela que na atualidade, considerando o cenário estudado, no contexto rural as pessoas apresentam maiores indicadores de sentimento de comunidade. A situação de pobreza multidimensional náo influenciou em diferenças significativas de sentimento de comunidade.

Os dados conduzem a problematizaçôes de que em uma sociedade fortemente marcada pelo individualismo e meritocracia, as pessoas podem apresentar elevados indicadores de bem estar, mesmo em contextos de fragilizaçáo dos laços sociais, do sentimento de comunidade e de redes de apoio social. Em se tratando do fenômeno da pobreza, tais perspectivas individualistas e reducionistas podem incidir sobre a perpetuação de uma cultura de naturalização da pobreza e culpabilização do pobre por sua condição.

Evidencia-se a necessidade do desenvolvimento de novas pesquisas que explorem as implicaçóes da pobreza no bem estar pessoal e no sentimento de comunidade em diferentes regióes do país. Assim como o desenvolvimento de estudos que possam explorar mais a fundo a relação das categorias com diversas variáveis (como renda, escolaridade) que contribuem para uma leitura da pobreza, a partir de uma perspectiva multidimensional.

\section{Referencias}

Accorssi, A. (2011). Materializaçóes do pensamento social sobre a pobreza (Tese de Doutorado). Pontifícia Universidade Católica do Rio Grande do Sul, Porto Alegre.

Amaro, J.P. (2007). Sentimento Psicológico de Comunidade: uma revisão. Análise Psicológica, 1(25), 25-33.

Bastos, A.C.S, Rabinovich, E.P, \& Almeida, M.B. (2011) Living the world of poverty: the researcher as participant/apprentice. Psychology and Developing Societies, 22(2), 221-247.

Bauman, Z. (2008). Vida para o consumo. Rio de Janeiro: Jorge Zahar.

Benatuil, D. (2003). El bienestar psicológico en adolescentes desde una perspectiva cualitativa. Psicodebate: Psicología, cultura y sociedad, 3, 43-58.

Cidade, E. C. (2012). Juventude em condiçôes de pobreza: modos de vida e fatalismo (Dissertação de Mestrado). Universidade Federal do Ceará, Fortaleza.

Cidade, E. C., Moura, J. F., \& Ximenes, V. M. (2012). Implicaçóes psicológicas da pobreza na vida do povo Latino-Americano. Psicologia Argumento, 30(68), 87-98.

Couto-Oliveira, V. (2007). Vida de mulher: gênero, pobreza, saúde mental e resiliência. Dissertação (Mestrado em Psicologia Clínica e Cultura). Universidade de Brasília, Brasília.

Cummins, R. A., Eckersley, R., Pallant, J., Van Vugt, J., \& Misajon, R. (2003). Developing a national index of subjective wellbeing: the Australian unity wellbeing index. Social Indicators Research. 64, 159-190. 
Dela Coleta, J., Lopes, J., \& Dela Coleta, M. (2012). Felicidade, bem-estar subjetivo e variáveis sociodemográficas em grupos de estudantes universitários. Psico-USF, 17, 129-139.

Diener, E., \& Seligman, M.E.P. (2004). Beyond Money: Toward an economy of well-being. Psychological Science in the Public Interest, 5(1), 1-31.

Elvaz, S., \& Moniz, M.J.V. (2010). Sentimento de Comunidade, qualidade de vida e satisfação com a vida. Análise Psicológica, 3 (28), 451-464.

Freitas, M. G., \& Montero, M. (2003). Las redes comunitarias. In Montero, M. (Org.) Teoria y práctica de la Psicología Comunitaria: la tensión entre comunidad y sociedad (pp.173-201). Buenos Aires: Paidós.

Garcia, E., \& Herrero, J. (2006). La comunidad como fuente de apoyo social: evaluación e implicaciones en los ámbitos individual y comunitario. Revista Latinoamericana de Psicologia, 38, 327-342

Góis, C.W.L. (2005). Psicologia Comunitária: atividade e consciência. Fortaleza: Publicaçóes Instituto Paulo Freire.

IPECE. (2012). Perfil Municipal de Fortaleza. Tema VIII: O Mapa da Extrema Pobreza. Informe $n^{\circ}$ 43. Fortaleza. Recuperado de http://www. ipece.ce.gov.br/informe/Ipece_Informe_43_05_ novembro_2012.pdf.

IPECE. (2013). Perfil Básico Municipal - Apuiarés. Recuperado de http://www.ipece.ce.gov.br/perfil_ basico_municipal/2013/Apuiares.pdf.

Lever, J.P., Piñol, N.L.G., \& Uralde, J.H. (2005). Poverty, psychological resources and subjective wellbeing. Social Indicators Research, 73(3), 375-408.

Lima, C.M., \& Valla, V. (2005). Religiosidade popular e saúde: fome de que? In: Anais Encontro Nacional de Pesquisa em Educação em Ciências. Bauru. Recuperado de www.nutes.ufrj.br/abrapec/venpec/ conteudo/artigos/3/doc/p637.doc

Loureiro, A.O.F, \& Suliano, D.C. (2009). As principais linhas de pobreza utilizadas no Brasil. Nota Técnica No 3 do de Pesquisa e Estratégia Econômica do Ceará (IPECE). Governo do Estado do Ceará. Recuperado de $<$ http://www.ipece.ce.gov.br/publicacoes/notas_ tecnicas/NT_38.pdf.

Marante, L.R.P. (2010). A reconstrução do sentido de comunidade: implicaçóes teórico-metodológicas no trabalho sobre a experiência de sentido de comunidade (Dissertação de Mestrado). Universidade de Lisboa, Lisboa.

Martínez, M. M. (2004). Comunidad y bienestar social. In M. Ochoa, M. Olaizola, C. Espinosa; M. Martínez
(Orgs.). Introducción a la Psicología Comunitaria (pp. 43-72). Barcelona: Editorial UOC.

McMillan, D.W., \& Chavis, D.M.G. (1986). Sense of community: a definition and theory. Journal of Community Psychology, 14, 1-23.

Montero, M.M. (2004). Introducción a la Psicología Comunitaria: desarrollo, conceptos y procesos. Buenos Aires: Paidós.

Morais, S.M.R.B.M. (2010). Viver na Alta de Lisboa: o impacto do Sentimento Psicológico de Comunidade e das relaçóes de vizinhança no Bem-Estar. (Dissertação de Mestrado). Instituto Universitário de Lisboa, Lisboa.

Moura Jr., J., Cidade, E.C., Ximenes, V.M, \& Sarriera, J.C. (2014). Concepçóes de Pobreza: um convite à discussão psicossocial. Temas em Psicologia, 22(2), 341-352.

Nepomuceno, B.B. (2013). Pobreza e saúde mental: uma análise psicossocial a partir da perspectiva dos usuários do Centro de Atenção Psicossocial (CAPS) (Dissertação de Mestrado). Universidade Federal do Ceará, Fortaleza.

Oliveira, G. F., Barbosa, G. A., Souza, L. E. C, Costa, C. L. P., Araújo, R. C. R., \& Gouveia, V. V. (2009). Satisfação com a vida entre profissionais da saúde: correlatos demográficos e laborais. Revista Bioética, $17(2), 319-334$.

Piovesan, A., \& Temporini, E. (1995). Pesquisa exploratória: procedimento metodológico para o estudo de fatores humanos no campo da saúde pública. Rev. Saúde pública, 29(4), 318-325.

Prado, M.A.M. (2005). Movimentos de Massa e Movimentos Sociais: aspectos psicopolíticos das ações coletivas. Revista de Ciências Humanas, (37), 47-65.

Prezza \& Contatini (1998). Sense of Community and Life Satisfaction: Investigation in Three Diferent Territorial Contexts. Journal of Community \& Applied Social Psychology, 8, 181-194.

Sarason, S. (1974). The psychological sense of community: Prospects for a community psychology. San Francisco: Jossey-Bass.

Sarriera, J. C., Ximenes, V. M., Bedin, L., Rodrigues, A. L., Schütz, F. F., Montserrat, C., \& Silva, C. L. (2012). Bem-estar pessoal de pais e filhos e seus valores aspirados. Aletheia, 37, 91-104.

Sen, A. (2010). Desenvolvimento como liberdade. São Paulo: Companhia das Letras.

Silva, L.B., Feitosa, M.Z. de S., Nepomuceno, B.B., Silva, A.M.S., Ximenes, V.M. \& Bomfim, Z.A.C. (2016) Apoio Social como modo de enfrentamento 
à pobreza. In V.M. Ximenes, B.B. Nepomuceno, E.C. Cidade, \& J.F, Moura Jr. (Orgs.) Implicaçôes Psicossociais da Pobreza: Diversidades e Resistências. (pp. 289-310). Fortaleza: Expressão Gráfica e Editora. Soares, S., Souza, L., Silva, W., Silveira, S.G., \& Campos, A. (2016). Perfil da Pobreza: Norte e Nordeste Rurais. Brasília: Centro Internacional de Políticas para o Crescimento Inclusivo. Recuperado de: http://www.ipc-undp.org/pub/port/Perfil_da_ pobreza_Norte_e_Nordeste_rurais.pdf.

Stotz, E. (2005). Pobreza e capitalismo. In V.V. Valla, E. N. Stotz, \& E.B. Algebaile (Orgs.). Para compreender a pobreza no Brasil (pp. 53-72). Rio de Janeiro: Contraponto: Escola Nacional de Saúde Pública, 2005.

Universidade Estadual do Ceará. (2011). Mapa da Criminalidade e da Violência em Fortaleza: perfil da SER V. Recuperado de <http://www.uece.br/labvida/ dmdocuments/regional_V.pdf $>$.
Ximenes, V.M., Moura Jr., J.F., Cruz, J.M., Silva, L.B., \& Sarriera, J.C. (2016). Pobreza multidimensional e seus aspectos subjetivos em contextos rurais e urbanos nordestinos. Estudos de Psicologia, 21(2),146-156.

Ximenes, V.M., \& Moura Jr, J.F. (2013). Psicologia Comunitária e comunidades rurais do Ceará: caminhos, práticas e vivências em extensão universitária. In F.J.F Leite \& M. Dimenstein (Orgs). Psicologia e contextos rurais (pp.453-476). Natal: EDUFRN.

\section{Endereço para correspondência:}

Bárbara Barbosa Nepomuceno

Rua República da Armênia, 900, Água Fria CEP: 60821-760 - Fortaleza/Ceará.

Email: bbnepomuceno@yahoo.com.br

Recebido em 04/01/2017

Aceito em 17/03/2017 